\title{
O desempenho no Decreto 7.508/2011 e o direito ao acesso aos serviços de saúde: caminhos para uma interpretação pós-positivista
}

The performance in Decree 7508/2011 and the right of access to health services: paths for a post-positivist interpretation

El desempeño en el Decreto 7.508/2011 y el derecho al acceso a los servicios de salud: caminos para una interpretación post-positivista.

RESUMO: O esvaziamento do direito à saúde em nome do princípio da reserva do possível está levando os legisladores a editarem 0 direito à saúde em suas regulamentações com base no pensamento gerencialista. Objetivou-se demonstrar essa tese através da análise crítica da noção de desempenho no Decreto 7.508/2011 que regulamenta os sistemas regionais de saúde no Sistema Único de Saúde. A finalidade foi construir um caminho téorico para a interpretação pós-positivista deste dispositivo infraconstitucional. Para isso, utilizou-se a técnica de revisão narrativa descrita por Rother para dispor do arcabouço teórico suficiente que expusesse os valores subjacentes ao texto de lei. Foi possível perceber que a lógica se materializa principalmente nos incentivos por desempenho que contradizem a organização sistêmica preconizada para o alcance da integralidade do cuidado em uma região de saúde. Pôde-se concluir que o Decreto detém forte conotação gerencialista e que pode cercear o direito ao acesso dos usuários aos serviços de saúde no âmbito de sua interpretação/operacionalização indo contra os cânones da própria fundamentação teórica da Saúde Coletiva.

Palavras-chave: Direito Sanitário. Sistema Único de Saúde. Lei Orgânica. Legislação Sanitária. Avaliação em Saúde.

ABSTRACT: To empty the right to health in the name of Reserve of the Possible Principle, lawmakers are editing the right to health in its regulations based on managerial thinking. The objective was to demonstrate this thesis through the critical analysis of the notion of performance in Decree 7508/2011, which regulates the regional health systems in the Unified Health System. The purpose was built a theoretical path to the post-positivist interpretation of this infraconstitucional dispositive. For this, we used the narrative review technique described by Rother to have sufficient theoretical framework that expose the values underlying the law text. It was possible to see that the logic had been concretized in performance incentives that contradict the systemic organization advocated for the achievement of comprehensive care in a health region. It can be concluded that the Decree has strong managerial connotation and may restrict the right to users' access to health

\footnotetext{
1 Especialista em Direito Sanitário pelo Instituto de Direito Sanitário Aplicado (IDISA). Doutor em Saúde Pública (Área de Concentração: Política, Gestão e Saúde). Professor Adjunto do Núcleo Integrado de Saúde Coletiva (NISC) da Universidade de Pernambuco (UPE) - Campus Santo Amaro, Recife, Pernambuco, Brasil. email: leonardo.carnut@gmail.com

2 Especialista em Direito Sanitário pelo Instituto de Direito Sanitário Aplicado (IDISA). Mestre em Direito pela Universidade Metodista de Piracicaba. Promotor de Justiça. Ministério Público do Estado de São Paulo. Brasil. email: jorgemasseran@uol.com.br
} 
services within their interpretation going against the canons of the theoretical foundation of Public Health.

Keywords: Health Law. Unified Health System. Organic Law. Health Legislation. Health Evaluation.

RESUMEN: El vaciamiento del derecho a la salud en el nombre del principio de la reserva del posible lidera los legisladores a modificar el derecho a la salud en su normativa basada en el pensamento gerencialista. El objetivo era demostrar esta tesis a través del análisis crítico de la noción de performance en el Decreto 7.508/2011 que regula los sistemas regionales de salud en el Sistema Único de Salud. El objetivo era construir un camino teórico para la interpretación post-positivista de este dispositivo infraconstitucional. Para esto, hemos utilizado la técnica de revisión narrativa descrito por Rother para disponer de suficiente marco teórico que expongan los valores que subyacen en el texto de ley. Era posible ver que la lógica se materializa principalmente en los incentivos de desempeño que contradicen la organización sistémica planificada para el alcance de la atención integral de una región sanitaria. Se puede concluir que el Decreto tiene fuerte connotación gerencialista y puede restringir el derecho de acceso de los usuarios a los servicios de salud dentro de su interpretación que va en contra de los cánones de la base teórica de la Salud Pública.

Palavras-Ilaves: Derecho Sanitario. Sistema Único de Salud. Ley Orgánica. Legislación Sanitaria. Evaluación en Salud.

\section{Introdução}

O controle jurisdicional do direito à saúde (1) (2) (3) (4) (5) (6) vem tornando cada vez mais questionável a sustentabilidade dos princípios fundamentais do SUS, dentre eles a integralidade do cuidado entendida como o acesso do usuário a todos os níveis do sistema (7) (8) (9)

O fato do "direito ao acesso aos serviços de saúde" não estar sendo efetivado no cotidiano dos sistemas regionais de saúde, especialmente no que tange aos serviços de maior complexidade, tem sido a principal causa deste controle. Na maior parte das vezes, o problema reside na incompletude da rede de atenção para tal prestação como documentado por diversos estudos (10) (11) (12) (13) (14) (15) (16) (17) (18) (19). Neste cenário, quando a gestão é acionada judicialmente, a defesa geralmente faz uso do argumento da "reversa do possível" (20) (21) sobrepondo-se ao princípio da preservação da dignidade da pessoa humana fundamentalmente nuclear caso do direito à saúde.

Contudo, um problema que parece estar sendo escamoteado é atividade legislativa que reforça esvaziamento do direito à saúde. Em nome da "reserva do possível", os legisladores estão "prima facie" editando o direito à saúde valendo-se da filosofia da nova 
gestão pública e de seus conceitos para cercear a amplitude deste direito. A new public managament (22) (23) (24) (25) desde 95, vem trazendo consigo a questão dos "resultados" como forma de viabilizar a solução do problema de uma máquina pública complexa, burocrática e "processualista" (23) (25) baseada numa promessa de maior agilidade na prestação de serviços ao 'consumidor-cidadão'. É daí que emerge seu principal álibi: a mensuração do desempenho.

O jargão da new public management vem sendo impregnado nos textos de lei, especialmente no âmbito da regulamentação dos parágrafos da constituição federal que versam sobre o funcionamento do Sistema Único de Saúde e sua operacionalização (26) (27). Em que pese a relevante tarefa de fazê-lo, parece que o direito à saúde vem perdendo sua potência interpretativa à luz do que Bisol (2012) (28) já identificava como um descompasso entre um sanitarismo de ponta em relação a um pensamento jurídico obsoleto. Em busca de uma segurança jurídica, o pensamento reformista do Estado brasileiro traduzido especialmente no Decreto 7.508/2011 chega à atividade legislativa em saúde e, se não bem repensada, pode passar despercebida e ferir os contornos progressistas que o direito à saúde detém no Brasil.

Assim, este estudo se trata de uma revisão narrativa (29), em uma perspectiva crítica, para analisar a noção de "desempenho" identificada no Decreto 7.508/2011 com o foco a favorecer o direito ao acesso aos serviços de saúde (30). A ideia de desempenho vem servindo de justificativa para criação de formatos de avaliação de serviços de saúde que, a depender dos resultados, podem ganhar ou perder incentivos e iniciar um processo de desconstrução da lógica sistêmica no qual o SUS está assentado. Este processo, para além do que está positivado, pode ser considerado um desmonte do conceito jurídico de saúde (31) (32) (33) por dentro e desta vez através de uma atividade legislativa aparentemente inócua. A intenção nesse manuscrito é problematizar os subsídios para uma interpretação pós-positivista desta norma, especialmente no que tange ao que se compreende por desempenho e sua (in)aplicabilidade.

Logo, este artigo esta dividido em seis partes. A primeira, mais histórica, narra as origens do gerencialismo na estrutura administrativa do Estado brasileiro. Na segunda, discorre-se sobre a centralidade dos "resultados" neste pensamento administrativo e suas incompatibilidades com a prestação de serviços de saúde. Na terceira, foca-se na noção de "desempenho" como norte avaliativo. A quarta se reserva a analisar os excertos do 
texto de lei do Decreto 7.508/2011 que remetem a noção de desempenho. Na quinta, traça-se uma interpretação legal à luz do pós-positivismo sobre a questão do desempenho no decreto estudado e por fim, na sexta, traçar-se-á brevíssimas considerações sobre o (re)direcionamento que a temática pode ganhar no contexto atual.

\section{A origem do paradigma gerencialista no setor público brasileiro e a busca por resultados}

A tese da presença de um Estado forte simboliza a possibilidade de garantia do acesso aos serviços de saúde, elemento fundamental na consolidação do direito à saúde em sentido lato. Contudo, historicamente falando, a formação do Estado Brasileiro vem passando por mudanças substantivas que respondem por parte da incapacidade de 0 Estado em promover o acesso aos serviços de forma adequada e de acordo com as necessidades da população.

Segundo Bresser-Pereira (1996) (22) é essencial para o capitalismo a clara separação entre o Estado e o mercado; a democracia só pode existir quando a sociedade civil, formada por cidadãos, distingue-se do Estado ao mesmo tempo em que o controla. Por isso, em face às exigências de novos papéis a esses agentes econômicos e a impregnação da ciência como organizadora da vida social, tornou-se necessário desenvolver um tipo de administração que partisse não apenas da clara distinção entre o público e o privado, mas também gerasse a separação entre o "político" e o "administrador público". Surge assim a administração burocrática moderna, racional-legal.

A implantação do paradigma burocrático na organização do Estado, rapidamente ganhou aceitação. Esta aceitação foi muito motivada por um contexto sócio-histórico onde se apontava a necessidade de combate ao patrimonialismo oriundo da formação do Estado brasileiro. Como afirma Freyre (1998) (34), a origem do Estado Patrimonial brasileiro se localiza na vinculação historicamente estabelecida entre "unidade familiar" e "unidade de produção" que se confundiam na Casa Grande. Por isso, racionalizar a gestão, naquele período, era uma reafirmação dos valores propriamente burocráticos na administração pública (22) que visam extirpar qualquer forma de manifestação do patrimonialismo fortemente expresso na tessitura social brasileira.

Contudo, no decorrer da consolidação do modelo burocrático no âmbito da administração pública, muitas mudanças significativas foram ocorrendo, em particular, 
relacionadas ao questionamento da "eficiência" das ações públicas frente às novas necessidades advindas do avanço das sociedades capitalistas, da agudização das relações conflituosas entre Estado-mercado e da ressiginificação do papel do Estado na responsabilidade pela vida dos cidadãos nos Estados Nacionais (22).

Neste momento, críticas relativas ao "tamanho" do Estado, à adoção de mecanismos de regulação econômica de inspiração Keynesiana e a pouca capacidade de resposta ágil e eficiente do Estado às demandas sociais emergentes se agravara. Pari passu às críticas relativas ao papel do Estado, a crise do petróleo em 1974 e globalização da economia após a queda do muro de Berlim com o fim de uma utopia comunista (35), evidenciaram ainda mais a problemática de um Estado-interventor. Não obstante, como solução a situação conjuntural, sugeriu-se o recuo do Estado em prol do reaquecimento econômico, como elencado na maioria dos projetos políticos neoliberais adotados no mundo afora (36).

Nesse novo projeto econômico, onde o primado da rapidez com controle de gastos e da eficiência com flexibilidade legal se impuseram como ordenamento social hegemônico. Outrossim, nada mais esperado que a máquina pública incorporasse essa filosofia na nova concepção do Estado e nas regras que regem a administração pública, como coloca Bresser-Pereira (1996) quando afirma que a atual reforma na grande crise do Estado dos anos 80 e na globalização da economia que redefinem as funções do Estado e da sua burocracia (22).

Nessa perspectiva, a tarefa de reformar o aparelho do Estado visando um maior desempenho das organizações públicas demandou muito mais do que um estímulo do poder econômico; requereu uma política pública para esse propósito (24). Portanto, diante desses desafios, em 1995 o governo Itamar Franco iniciou a Reforma Gerencial do Estado, incutindo no âmbito público o que se convencionou chamar de um "novo paradigma" de gestão pública ou "paradigma gerencialista", que tem como missão principal a ênfase nos resultados (22).

Em que pese toda discussão sobre: se a nova gestão pública é ou não um novo paradigma (37), se é um retorno às conclusões maquiavélicas (38), ou ainda se foi apenas uma Reforma Administrativa ao invés de uma Reforma de Estado (39), segundo BresserPereira (1996) (22) o fato é que a necessidade deste modelo decorria não só da diferenciação de estruturas e complexidade crescente da pauta de problemas a serem enfrentados pelo Estado, mas também de legitimação da burocracia perante as demandas 
da cidadania. Como afirma Behn (1998) a nova gestão pública é uma nova conceituação da administração pública que consiste de vários componentes dentre eles medir e premiar organizações e indivíduos com base no cumprimento das metas exigidas de performance assim como manter uma atitude aberta a respeito de quais propósitos públicos devem ser desempenhados pelo setor privado, e não pelo setor público (23).

Em síntese, trata-se de uma reestruturação das organizações públicas para atribuirIhes flexibilidade administrativa e responsabilização (25). Para materialização dessa proposta, a contratualização de resultados é uma das ferramentas mais utilizadas, tornando-se, portanto, um mecanismo cada vez mais incorporado nas políticas públicas. Daí então, segundo Pacheco (2004) (24), os resultados se tornam o alvo em potencial das organizações públicas que passam a focar na melhoria de seus desempenhos, para isso tentando equacionar adequadamente os requisitos de autonomia (de gestão) e controle (de resultados).

\section{A apreciação dos resultados e do desempenho sob à lógica gerencialista em saúde}

Mensurar resultados constitui, então, um dos pilares das reformas em curso em diversos países nas últimas duas ou três décadas e que, no Brasil, vem acontecendo a passos largos. A contratualização de resultados e a remuneração variável por desempenho têm sido a principal ferramenta gerencial adotada deste modelo e tem gerado polêmicas tanto entre adeptos como entre críticos (24).

A centralidade nos resultados alcançados pelas organizações não podem ser analisados no seu "estado bruto" ou em perspectivas dicotômicas como "alcançado" ou "não-alcançado". As medições que identificam o grau de cumprimento das metas organizacionais estabelecidas entram no bojo da discussão e por isso, captar o desempenho dessas organizações passa a ser primordial. Diversos estudos demonstram como as organizações procuram sistemas de medição de desempenho que caracterizem suas situações dentro das conjunturas em que se inserem (40) (41) (42) (43) (44) (45). No caso da saúde, entendida economicamente como pertencente ao setor de serviços (46), seu sistema de medição deve levar em consideração também indicadores que estivessem relacionados à capacidade de medir a determinação dos resultados.

Com efeito, medir determinado processo só se justifica se ele se propõe a ser passível de avaliação. A avaliação constitui um instrumento essencial de apoio à gestão 
pela sua capacidade de melhorar a qualidade da tomada de decisões. Um obstáculo para uma utilização mais ampla da avaliação na tomada de decisão nos serviços de saúde é que a sua implementação requer recursos e tempo, o que dificulta a sua utilização para problemas que necessitem de soluções imediatas. Nessas situações, que são frequentes quando se trata da saúde de pessoas e da população, somente a existência de um conhecimento acumulado, decorrente de avaliações passadas ou previamente planejadas, pode contribuir para a tomada de decisão (47).

A palavra avaliação, em seu sentido lato, consiste em atribuir valor a algo (48). Nesta acepção, o termo avaliação refere-se ao ato ou efeito de avaliar (49), ou seja, conferir valor, manifestar-se em relação a alguma coisa, sem compromisso, no entanto, com o fundamento desse juízo ou com um método específico. Dentre as mais diversas formas de conceituação que a avaliação pode ter para o trabalho com o desempenho, talvez a de Arnold (1971) (50) se adéque mais. Para este autor, avaliação é a retroação planejada $e$ sistemática de informações necessárias para guiar a ação futura.

Um equívoco comum entre os tomadores de decisão de cuidados de saúde é pensar a avaliação [em saúde] como simplesmente medição de desempenho. A medição do desempenho é principalmente uma ferramenta de gestão enquanto que a avaliação é uma ferramenta de pesquisa (51). A medição de desempenho concentra-se frequentemente em um limitado conjunto de indicadores quantitativos (52) o que não descrevem completude de uma organização, menos de se esperar de um sistema de saúde.

\section{O desempenho e a avaliação meritocrática}

Nessa esteira o desempenho alcança o proscênio da discussão. O vocábulo desempenho apresenta diversas significações a depender do autor e da seara científica na qual se localiza o termo.

No sentido lato, pode-se dizer que desempenho (ou performance) é um conjunto de características ou capacidades de comportamento e rendimento de um indivíduo (53), de uma organização (54) ou grupo ou de seres humanos (55), de animais (56) ou de outros seres vivos (57), de máquinas ou equipamentos (58), de produtos (59), sistemas (60), empreendimentos (61) ou processos (62), em especial quando comparados com metas, requisitos ou expectativas previamente definidos. Já outros autores (63), em sentido mais estrito, definem desempenho como uma ação, atuação ou comportamento qualificados a 
partir de uma expectativa. Para Siqueira (2002) (64) o desempenho é uma defasagem a ser mensurada a partir de uma expectativa criada sobre determinado comportamento.

O desempenho está relacionado à lógica de superação de expectativas que atribuem um mérito "funcional" àquele que executou algo além do esperado. Não obstante, o desempenho pode ser entendido como uma gradação de resultados conceitualmente relacionados à busca de um prêmio por mérito atingido e, portanto, compõem a lógica da meritocracia. Contudo, no paradigma gerencial o desempenho ficou associado apenas à produtividade e à quantidade de trabalho (65). O fato é que bons desempenhos, em sistemas meritocráticos, são incentivados pela premiação. $O$ foco de abordagem de um processo que avalia o desempenho de determinado ente é a relação essencial existente entre contribuição versus retribuição (66).

Assim, a arquitetura dos modelos de avaliação de desempenho para sistemas de saúde que vão ser construídos livremente inspirados na coerência da meritocracia avaliativa (67) (68). Em cumprimento às resoluções do Conselho Executivo da OMS, em maio de 2001, a Organização Pan-americana da Saúde realizou uma consulta regional sobre o Relatório Mundial de Saúde 2000 (World Health Report 2000). Nesta ocasião, considerou-se que a avaliação de desempenho não deve ser um fim em si mesma e nem ser encaminhada como um exercício puramente acadêmico, mas deve orientar o desenvolvimento de políticas, estratégias e programas dos sistemas de saúde, além de estar centrada na avaliação quantitativa e qualitativa do grau de realização de objetivos e metas dos sistemas.

Como bem lembra Klazinga (2012) (68), apesar de poder ajudar na construção de dados estatísticos longitudinais da população, a mensuração dos resultados de sistemas de saúde é desafiadora, sobretudo quando tais resultados podem ser atribuídos ao atual desempenho dos serviços de saúde. A despeito do desafio da mensurabilidade, o desafio da gestão reside em como estabelecer associação entre mensuração de resultados e iniciativas políticas tais como financiamento (associação da alocação de recursos pelo desempenho) ou programas nacionais de melhoria da qualidade.

A principal crítica aos modelos de avaliação de desempenho para sistemas de saúde segundo Champagne e Contandriopoulos (2005) (67) reside no fato de que estes parecem ou terem emergido dos dados disponíveis, ou terem sido emprestados de outro contexto, em ambos os casos, sem reflexão a respeito do seu conteúdo. Algo que parece ser uma 
questão difícil de resolver pela tensão que existe entre o particular e o geral. Haja vista, como expõe Tanaka e Tamaki (2012) (47) a gestão dos serviços de saúde tem que levar em consideração tanto aspectos internos - organização e funcionamento do serviço como aspectos externos - o seu papel no sistema de saúde e o impacto na saúde da população (68).

Em extensa revisão bibliográfica, Hoffman et al (2012) (69) identificaram 41 quadros teóricos diferentes sobre os tipos de estudos de sistema de saúde o que demonstra sua imensa pluralidade e questiona uma possível comparabilidade entre eles. Em estudo posterior, Smith e Papanicolas (2012) (70) identificaram que todos os sistemas de saúde apresentam em comum pelo menos os seguintes domínios que poderiam ser utilizados para a avaliação de seus desempenhos: a) saúde da população; b) resultados [da prestação] dos serviços de saúde; c) equidade; d) proteção financeira; e) capacidade de resposta; e, f) eficiência.

No entanto, dentre tantas divergências a respeito do tema, nenhum autor questiona o quão ideológico esses modelos, de fato, aparentam ser. Fortemente vinculados ao exercício prático do que apregoa o paradigma gerencialista, suas dimensões de mensuração expressam a carga ideológica de uma gestão estatal com característica de um poder dominante, baseada no reducionismo técnico do gestor e que se desprende do real objetivo desse tipo de mensuração que é a verificação de uma melhor prestação da atenção à saúde a diversos cidadãos. Uma consequência prática disso pode ser vista quando a avaliação se torna um simples instrumento de produção de ranqueamentos. Assim, desprende-se desta o potencial transformador que a avaliação pode oferecer, por sua vez se incutindo uma lógica competitiva, que o reduz o objeto da avaliação, amesquinha certos processos/modelos avaliativos e, por vezes, gera resultados nos quais os sistemas não se reconhecem (71).

A forma como as dimensões desses modelos de avaliação de desempenho de sistema de saúde são escolhidas, reflete claramente uma lógica organizacional de inspiração privatista, comprometida com a reprodução do status quo da gerência capitalista e que ignora (ou minoram a importância) do ponto de vista de quem recebe o cuidado. Esse aspecto remete a profunda reflexão que deve ser feita a respeito da lógica gerencialista como mecanismo orientador expresso na construção desses modelos. 


\section{O Decreto n. 7.508/2011: a conformação de sistemas regionais de saúde, o direito ao acesso aos serviços e a questão do desempenho}

O Decreto 7.508/2011 é a expressão legal regulamentadora da conformação de Sistemas Regionais de Saúde que visam, através de um instrumento contratual interfederativo (Municípios, Estado, e por vezes a União) construir um sistema de cuidado em rede que ofereça a integralidade do cuidado em uma escala geográfica territorialmente delimitada (72).

Neste sentido, o primeiro conceito disposto neste decreto é o de região de saúde. De extrema importância para definir as políticas públicas no SUS, uma vez que os entes da federação devem estar envolvidos com responsabilidades iguais, este é um espaço geográfico bem definido no Decreto 7.508/11 e é uma forma de definir responsabilidades, facilitar transportes, compartilhar infraestrutura, planejar ações e suas execuções de serviços, como afirma o art. $2^{\circ}$. Inciso I. Não há como garantir a integralidade do cuidado sem que as redes de atenção não estejam articuladas em níveis de complexidade como preconiza a definição de regiões de saúde acima descrita para fins de garantir a integralidade da assistência, assim seja caracterizada a necessidade do usuário pelo serviço de âmbito especializado.

Levando-se em consideração que o acesso universal é a prerrogativa jurídica de que todos têm o direito de acessar e usufruir das ações e serviços do sistema de saúde, o fato de sua gratuidade ser garantida no art. 43 da lei 8.080, é fundamental para que a responsabilidade das famílias e das pessoas na manutenção de sua própria saúde seja levada em consideração (parágrafo único, art. $2^{\circ}$. $\S 2^{\circ}$. da Lei 8.080). Isso não significa, portanto, que o usuário deva acessar o sistema de serviços de saúde para aquilo que não seja, reconhecidamente, uma doença ou agravo instalado.

Para facilitar a integralidade do cuidado, o usuário deve estar inserido na região a qual faz parte, respeitando as portas de entrada, preferencialmente através da atenção básica como coloca o art. 9․․ Assim, inserido na rede, respeitando as regiões de saúde ele pode fazer uso dos serviços oferecidos para ter direito ao acesso a todos os níveis de atenção. Contudo, a responsabilidade da constituição do cuidado em rede também está assentada na necessidade de comunicabilidade entre os serviços de saúde, que, na conjuntura atual, encontram-se totalmente fragmentados (73), o que vem sendo reconhecido como atomização dos serviços. 
Assim, os entes federados (Estados e municípios primordialmente) devem tecer o desenho das redes de atenção através da definição político-sanitária das áreas geográficas onde se conformará a integralidade do cuidado (ou assistência) à saúde em determinada região, conforme afirma o decreto no art. 20. Haja vista que a região de saúde não se constitui como um ente federado, as atribuições e competências relativas à constituição do cuidado em rede apresentam dificuldades. A principal trata-se do favorecimento à fragmentação dos serviços em detrimento à organização em rede, pois é evidente que essas atribuições/competências devem ser partilhadas com os entes municipais e estadual (e por vezes a união). Assim sendo, o decreto tenta normatizar a articulação entre esses entes, com fins de configurar regiões de saúde com responsabilidades compartilhadas celebrado através de um contrato interfederativo (Contrato de Organizativo de Ação Pública da Saúde - Art. 2o. Inciso 2o. Decreto 7.508/2001) o que deveriam favorecer a integralidade em nível locorregional.

É pertinente lembrar, nesse sentido, que o direito à saúde, antes ampliado (31) apresentará restrições no tocante a oferta em nível locorregional. O fato é que há uma impossibilidade sanitário-econômica de se oferecer todos os tipos de serviços em um escala geográfica reduzida. Logo, para garantir a integralidade, sem contudo, deixar a gestão sanitária pública vulnerável às ações judiciais que invoquem a diretriz da integralidade como argumento, é necessário tomar a integralidade restrita à um padrão ("padrão de integralidade") preconizada na legislação vigente no artigo art 21. e 25. do decreto 7.508 quando se institui a Relação Nacional de Ações e Serviços de Saúde (RENASES) e Relação Nacional de Medicamentos Essenciais (RENAME).

Para avaliar o funcionamento adequado deste sistema regional, entra em cena a questão do desempenho. O Decreto 7.508/2011 apresenta uma proposta de apreciação do desempenho que se encontra descrito nos artigos $2^{\circ}$. Inciso II, V, Caput do art. 35., art. 35 $\S 20$ e art. 41. O termo desempenho neste decreto, como bem expressa o texto de lei, apresenta-se como elemento parâmetro para premiação através de recursos financeiros para aqueles sistemas regionais que detenham desempenhos "satisfatórios". Em que pese toda a discussão teórica tecida nas seções anteriores, para fins de operacionalização dessa métrica, o governo federal, recentemente elaborou um índice de avalição de Desempenho para o Sistema Único de Saúde (IDSUS) que servirá de instrumento oficial 
da gestão para avaliar os Sistemas Regionais de Saúde de conceder-lhes (ou não) os incentivos (premiação) financeiros que lhes couberem.

O Índice de Desempenho do SUS (IDSUS) é um indicador síntese, que faz uma aferição contextualizada do desempenho do Sistema de Único de Saúde (SUS) quanto ao acesso (potencial ou obtido) e à efetividade da Atenção Básica, das Atenções Ambulatorial e Hospitalar e das Urgências e Emergências. A partir da análise e do cruzamento de uma série de indicadores simples e compostos, o IDSUS avalia o Sistema Único de Saúde que atende aos residentes nos municípios, regiões de saúde, estados, regiões, bem como em todo país (74).

É importante destacar que, em função da grande diversidade (demográfica, cultural, socioeconômica, geográfica, etc.) dos territórios do país, não seria adequado realizar uma classificação que apenas posicionasse, em ordem crescente ou decrescente, os municípios brasileiros. Assim, para realizar uma avaliação mais justa, a análise comparativa das notas do IDSUS deve ser feita por meio dos grupos homogêneos. Apenas dentro deles, por apresentarem características similares entre si, é possível traçar um paralelo minimamente comparativo (74).

\section{O desempenho gerencialista do Decreto $n$. 7.508/2011 e as bases para interpretação legal à luz do pós-positivismo jurídico}

De posse das descrições normativas apresentadas no Decreto 7.508/201, é possível observar que toda a conformação de sistemas regionais de saúde e sua organização legal para busca da integralidade do cuidado pode ser, na prática, alcançada de várias formas. Nesse sentido, é que a questão da avaliação do desempenho e a formulação legal dada a esta avaliação é passível de diversas interpretações.

A partir de como a legislação será interpretada pelo judiciário, a depender do paradigma constitucional em que o juiz se apoie e a conclusão do que venha a ser um bom ou mal desempenho irá variar significativamente.

$\mathrm{Na}$ atualidade, em superação ao paradigma positivista (ou dogmática jurídica) de interpretação da norma (Escola da Exegese), na qual a aplicação do Direito se dá de forma mecânica, consubstanciada na subsunção (75), discute-se a aplicação do paradigma póspositivista como forma de interpretação legal que se oriente na congregação de outros 
fatores explicativos da coisa a ser julgada, que transcende necessariamente a aplicação da norma restrita ao descrito no texto de lei (76).

Em contraponto ao positivismo jurídico, especialmente pelo fato de que o momento histórico ora vivenciado, constitucionalmente falando, vive-se um tipo de constitucionalismo pós-moderno ou pós-positivo que tenda transcender as características acima descritas. $\mathrm{O}$ pós-positivismo jurídico, procurando demonstrar que a pretensão de superação do positivismo jurídico, dominante no século $\mathrm{XX}$, concentra-se na resolução do problema que envolve o poder discricionário do julgador bem como o da determinação do direito no caso concreto, de modo a alcançar a conciliação entre validade formal e validade material (legitimidade). Em outras palavras, o aplicador do direito já não está adstrito a uma atividade meramente silogística, de simples exegese, mas a um papel construtivo, cujo norte é a tutela e a efetividade dos direitos fundamentais, entendidos como direitos individuais, sociais, políticos e econômicos (75).

No âmbito nacional, a Carta Constitucional brasileira de 1988 consagrou como seu fundamento, dentre outros, a dignidade da pessoa humana (art. 10, III CF/88) (32) do qual o direito à saúde (e por consequência seu acesso aos serviços) está intimamente relacionado. A Constituição Federal, que se apresenta para o povo nacional como uma verdadeira antítese das duas décadas anteriores achou um meio de consagrar que o Estado servia ao homem e não o contrário ingressando, também, na era do póspositivismo, que, praticamente suplantando a velha dicotomia direito natural $\mathrm{x}$ direito positivo, consagrou que o direito positivo estava imerso em valores morais e éticos que deviam nortear a atuação estatal (77).

A dignidade humana, tida por alguns autores como o nascedouro de todos os outros direitos fundamentais insertos na Constituição Federal é entendida como o centro ético do Texto Magno, atuando como pré-compreensão de todo o texto, funcionando como um vetor interpretativo do ordenamento jurídico, da atuação estatal e da ação privada, possuindo, ainda, além de seu caráter objetivo, inegável caráter subjetivo (77).

Portanto, a dignidade humana é dotada de um status de valor pré-constituinte e de hierarquia supraconstitucional. Ao lado daqueles que enumeram a dignidade humana como superprincípio. Dar à dignidade humana status preponderante sobre as demais normas constitucionais é a tônica do constitucionalismo moderno, sendo, ademais, da natureza do pós-positivismo (77). 
O pós-positivismo jurídico é a superação do legalismo estrito e traz de volta a discussão dos valores éticos ao Direito, com os princípios passando a integrar o moderno constitucionalismo, cuja normatividade encerra a unidade do sistema e condiciona a atividade do intérprete. Além daqueles princípios tradicionais, como o Estado Democrático de Direito, a igualdade e a liberdade, a Constituição, enquanto sistema aberto de valores consolida novos princípios da razoabilidade e da dignidade da pessoa humana, os quais estão assegurados pelo acesso à justiça e pela efetividade da prestação jurisdicional, todos considerados direitos fundamentais insuscetíveis de mitigação (78).

No pós-positivismo, não existe a busca pela verdade nos mesmos moldes que há no positivismo. Por reconhecer que não se pode aplicar a metodologia das ciências naturais ao direito e por não ser possível descobrir a verdade no mundo intersubjetivo que é o mundo do direito, "a epistemologia jurídica inerente ao pós-positivismo recusa o conceito de verdade como conceito central do conhecimento jurídico" (79) (80).

Símbolo do "pós-positivismo", onde os textos constitucionais estão imersos em valores cultuados pela sociedade - valores positivados e, portanto, com eficácia normativa - a dignidade da pessoa humana suplanta o frio positivismo, onde barbáries e atrocidades eram cometidas em nome da lei; esta, surda, muda e cega aos anseios sociais, diferentemente da concepção atual de lei e, principalmente, de constituição (77).

O pós-positivismo pretende, portanto, a promoção do reencontro da ética com o direito, por meio de um conjunto de ideias difusas, inovando sua aplicação sem substituí-la, combatendo, entretanto, o poder discricionário pregado por autores como o normativista Kelsen e também por Hart, sem, contudo, voltar ao legalismo mecanicista da Escola da Exegese do século XIX, bem como fazer uso dos metafísicos preceitos da escola jusnaturalista (75).

Assim, no pós-positivismo suas principais marcas são a ascensão dos valores e o reconhecimento da normatividade dos princípios, fundamentando que a dogmática tradicional fomentou-se sob o mito da objetividade do Direito e da neutralidade do intérprete, tendo encoberto seu caráter ideológico bem como sua instrumentalidade à dominação econômica e social. 


\section{Considerações Finais}

Diante de todos os elementos teóricos trazidos no bojo da discussão do direito ao acesso aos serviços de saúde e a constituição de uma avalição de desempenho de sistemas que podem ser interpretadas por várias lógicas teórico-jurídicas é possível dizer que há vários caminhos interpretativos para questão do desempenho no Decreto $7.508 / 2011$.

Com base em uma interpretação pós-positivista, pode-se admitir que esta noção de desempenho apresenta forte conotação gerencialista e a depender do caso, pode cercear o direito ao acesso dos usuários aos serviços de saúde no âmbito de sua interpretação/operacionalização indo contra os cânones da própria fundamentação teórica em saúde coletiva.

Desalojar esses elementos que subjazem o texto de lei é fundamental para desconstrução da falsa ideia de neutralidade axiológica destes dispositivos, especialmente quando se tratam da defesa da operacionalidade dos direitos sociais como neste caso do direito ao acesso aos serviços em uma rede de atenção em um sistema regional de saúde. Cremos, portanto, que o caminho a ser perseguido no amparo ao direito à saúde perpassa por este modelo de interpretação.

Este trabalho é derivado da monografia de conclusão de especialização de Leonardo Carnut cujo orientador foi Jorge Alberto Mamede Masseran. Ambos participaram igualmente da confecção do trabalho.

\section{Referências}

1 Costa AB, Júnior JGS, Delduque MC, Oliveria MSC, Dallari SG. (orgs). O direto achado na rua - introdução crítica ao direito à saúde. Brasília CEAD: UnB. 2009, 460 p.

2 Brasil. Ministério da Saúde. Secretaria de Gestão do Trabalho e da Educação na Saúde. Departamento de Gestão da Educação na Saúde. Direito sanitário e saúde pública / Ministério da Saúde, Secretaria de Gestão do Trabalho e da Educação na Saúde, Departamento de Gestão da Educação na Saúde; Márcio lorio Aranha (Org.) - Brasília: Ministério da Saúde, 2003. 2 v. :il. - (Série E. Legislação de Saúde). 
3 Delduque MC, Marques SB. O direito social à saúde deve ser garantido por políticas públicas e decisões judiciais. Temas atuais de direito sanitário/organizadora: Maria Célia Delduque - Brasília : CEAD/FUB, 2009. 128 p. 121-128.

4 Aith F, Saturnino LTM, Diniz MGA, Monteiro TC. (orgs.). Direito Sanitário: Saúde e Direito, um Diálogo Possível. Belo Horizonte: ESP-MG, 2010. 464 p.

5 Cristóvam JSS. Direitos sociais e controle jurisdicional de políticas públicas: algumas considerações a partir dos contornos do Estado Constitucional de Direito. 2011. Acessado em: http://jus.com.br/revista/texto/19437/direitos-sociais-e-controle-jurisdicional-depoliticas-publicas.

6 Delduque MC, Júnior JGS, Costa AB, Alves SMC, Pereira MF, Cardoso AJC. (orgs.). El derecho desde la calle : introducción critica al derecho a la salud. Brasília : FUB, CEAD, 2012, $390 \mathrm{p}$.

7 Brasil. Lei 8.080 de 19 de setembro 1990. Diário Oficial da República Federativa do Brasil, Poder Legislativo, Brasília, DF, 12 set. 1990a, Seção 1, p 1.

8 Brasil. Portaria de Diretrizes e Normas para a Atenção Básica. Estabelece a revisão de diretrizes e normas para a organização da Atenção Básica, para o Programa de Saúde da Família e para o Programa de Agentes Comunitários de Saúde - PACS e institui a Política Nacional de Atenção Básica, 2006.

9 Santos L, Andrade LOM. SUS: o espaço da gestão inovada e dos consensos interfederativos: aspectos jurídicos, administrativos e financeiros. $2^{\mathrm{a}}$. Edição. Campinas SP: Editora Saberes. 2009, 165 p.

10 Sá CSMB, Campos CMM, Souza CEM, Nunes EGA, Brito MNLS. Fragilidades e potencialidades da rede de atenção à saúde bucal de Solidão-PE. J Manag Prim Health Care 2011; 2(2):3-6.

11 Sousa AM, Lyra A, Freire RC. A rede de atenção à saúde bucal: a realidade do município de Caruaru. J Manag Prim Health Care 2011; 2(2):7-10.

12 Santos MAS, Cruz JB, Silva VR. Desafios da regionalização da assistência à gestante e ao parto na V GERES, Garanhuns, Pernambuco. J Manag Prim Health Care 2011; 2(2):1114.

13 Rêgo DMA, Campos MMA, Vieira MJS. Potencialidades e fragilidades da rede de atenção ao pré-natal no município de João Alfredo-PE. J Manag Prim Health Care 2011; 2(2):15-18. J Manag Prim Health Care 2011; 2(2):24-29.

14 Oliveira D, Ricarte L, Cristine S. Potencialidades e fragilidades: saúde da mulher no município de Limoeiro. J Manag Prim Health Care 2011; 2(2):19-23. 
15 Araújo CCF, Pontes JL, Pontes TL. Potencialidades e fragilidades da rede de atenção à saúde da mulher no município de Surubim. J Manag Prim Health Care 2011; 2(2):24-29.

16 Maia AAA, Melo EH, Santos JCV; Carvalho LCR, Saborido TKAA. Câncer de colo de útero: organização e análise do cuidado em rede no município de Garanhuns-PE. J Manag Prim Health Care 2011; 2(2):30-35.

17 Cabral ALN, Lima HDR, Cabral HLO. Potencialidades e fragilidades da rede de atenção à saúde no controle da hipertensão arterial no município de Correntes, Pernambuco. J Manag Prim Health Care 2011; 2(2):36-40.

18 Souza BMB, Vasconcelos CC, Tenório DM, Lucena MGA, Holanda RLT. Potencialidades e fragilidades da rede de atenção às urgências e emergências na $V$ regional de saúde, Garanhuns-PE. J Manag Prim Health Care 2011; 2(2):41-45.

19 Filho DPA. Potencialidades e fragilidades da rede de atenção à assistência farmacêutica no município de Tabira. J Manag Prim Health Care 2011; 2(2):46-49.

20 Botelho A. O público e o privado no pensamento social brasileiro. Botelho A, Schwarcz LM. Cidadania, um projeto em construção. São Paulo: Claro Enigma, 2012, p. 48-59.

21 Ferraz OLM, Vieira FS. Direito à Saúde, Recursos Escassos e Equidade: Os Riscos da Interpretação Judicial Dominante. DADOS. Revista de Ciências Sociais. 2009; 52:223-251.

22 Bresser-Pereira LC. Da administração pública burocrática à gerencial. Revista do Serviço Público 1996; 47(1):1-28.

23 Behn RD. O novo paradigma da gestão pública e a busca pela accountability democrática. Revista do Serviço Público. 1998; 49(4):5-43.

24 Pacheco RS. Mensuração do desempenho no setor público: os termos do debate. Cadernos Gestão Pública e Cidadania 2009; 14(55):149-161.

25 Garces A, Silveira JP. Gestão pública orientada por resultados no Brasil. Revista do Serviço Público 2002; 53(4):53-77.

26 Brasil. Ministério da Saúde. Secretaria de Gestão Estratégica e Participativa. Decreto no 7.508, de 28 de junho de 2001 : regulamentação da Lei no 8.080/90 / Ministério da Saúde. Secretaria de Gestão Estratégica e Participativa. - Brasília: Ministério da Saúde, 2011. 16 p. - (Série E. Legislação de Saúde).

27 Brasil. Lei complementar 141, de 13 de janeiro de 2012. Regulamenta o § 3o do art. 198 da Constituição Federal e dá outras providências. Brasília, DF, 2011.

28 Bisol J. Post 4: Um pensamento jurídico obsoleto para um sanitarismo de ponta. In: OLIVEIRA, N.A. Direito Sanitário: oportuna discussão via coletânea de textos do 'blog 
Direito Sanitário: Saúde e Cidadania'. ANVISA, CONASEMS, COSEMS: Brasília: 2012, p., 49-51.

29 Rother ET. Editorial: Revisão sistemática X revisão narrativa. Acta Paulista de Enfermagem. 2007; 20(2):v-vi.

30 Simões C. Os direitos sociais na Constituição de 1988 - Conceito. In: Teoria e crítica dos direito sociais: O Estado Social e o Estado Democrático de Direito. São Paulo: Cortez, 2013, p. 171-201.

31 World Health Organization (WHO) as adopted by the International Health Conference, New York, 19-22 June, 1946; signed on 22 July 1946 by the representatives of 61 States (Official Records of the World Health Organization, no. 2, p. 100) and entered into force on 7 April 1948.

32 Brasil. Constituição. Constituição da República Federativa do Brasil. Brasília, DF, Senado Federal, 1988.

33 Brasil. Lei 8.142 de 28 de dezembro de 1990. Dispõe sobre a participação da comunidade na gestão do Sistema Único de Saúde (SUS) e sobre as transferências intergovernamentais de recursos financeiros na área da saúde e dá outras providências. Diário Oficial da República Federativa do Brasil, Poder Legislativo, Brasília, DF.

34 Freyre G. Casa-Grande \& Senzala. 34ª edição. Rio de Janeiro:Record, 1998, p. 372.

35 Hobsbawm E. O século: vista aérea. Olhar panorâmico: In: Era dos extremos. O breve século XX 1914-1991. São Paulo: Companhia das Letras, p. 11-26, 1995.

36 Laurell A. Avançando em direção ao passado: a política social no neoliberalismo. In: pp.151-178. Estado e políticas sociais no neoliberalismo. 3ª . ed. - São Paulo: Cortez, 2002.

37 Castiel LD, Póvoa EC. Dr. Sackett e "Mr. Sacketter"... Encanto e desencanto no reino da expertise na medicina baseada em evidências. Cad. Saúde Pública. 2001; 17(1):205214.

38 Maquiavel N. O Príncipe. São Paulo: DPL Editora, 2008.

39 Rezende FC. Por que as reformas administrativas falham? Rio de Janeiro: Editora FGV, 2004, 132 p.

40 Motta PR. Modernização da administração pública brasileira nos últimos 40 anos.

Revista de Administração Pública 2007; Ed especial: 87-96.

41 Atkinson AA, Waterhouse JH, Wells RBA. Stakeholder Approach to Strategic Performance Measurement. Sloan Management Review 1997; 38:25-37. 
42 Bitici US, Turner T, Begemann C. Dynamics of performance measurement systems. International Journal of Operations \& Production Management 2000; 20(6):692-704.

43 Busanello EC. Um panorama dos estudos sobre avaliação de desempenho logístico Indicadores e sistemas de mensuração. Anais XXXV Encontro da ANPAD, 2011.

44 Verbeeten FHM, Boons ANAM. Strategic priorities, performance measures and performance: an empirical analysis in Dutch firms. European Management Journal 2009; 27:113-128.

45 Fitzgerald L, Johnston R.; Brignall S, Silvestro R, Voss, C. Performance Measurement in Service Business. London: CIMA, 1991.

46 Meirelles DS. O conceito de serviço. Revista de Economia Política. 2006; 26(1):119136.

47 Tanaka OU, Tamaki EM. O papel da avaliação para a tomada de decisão na gestão de serviços de saúde. Ciênc. saúde coletiva 2012; 17(4):821-828.

48 Aguilar MJ, Ander-Egg E. Avaliação de serviços e programas sociais. Petrópolis: Editora Vozes; 1994.

49 Ferreira ABH. Novo Dicionário da Língua Portuguesa. Rio de Janeiro: Editora Nova Fronteira. 1986.

50 Arnold MF. Evaluation: a parallel process to planning. In: Arnold MF et al. (Eds.). Administering health systems: issues and perspectives. Chicago: Aldine; 1971.

51 Bonar Blalock A. Evaluation research and the performance management movement: from estrangement to useful integration? Evaluation 1999; 5(2): 117-149.

52 Canada. Canadian Institute of Health Research. BOWEN, S. A guide to evaluation in health research. Department of Public Health Sciences, School of Public Health. University of Alberta, 2012. Acessado em: 08/10/2012 Disponível em: http://www.cihrirsc.gc.ca/e/documents/kt_Im_guide_evhr-en.pdf.

53 Procópio ML. "Reflexões sobre a Avaliação Individual de Desempenho." Portal Guia RH. Acessado em 10/11/2010 Disponível em: http://www.rh.com.br/Portal/ Desempenho/Artigo/3163/reflexoes-sobre-a-avaliacao-individual-de-desempenho. html.

54 Júnior FH, Ruiz FM, Corrêa HL. A Evolução dos Métodos de Mensuração e Avaliação de Desempenho das Organizações. Resumo ANPAD. 2005.

55 Reifschneider MB. Considerações sobre avaliação de desempenho. Ensaio: aval. pol. públ. Educ. 2008; 16(58):47-58. 
56 Rink B. Equitação e liderança. Palestra de para os alunos do Curso de Instrutor de Equitação/2004 na Escola de Equitação do Exército, em 16/03/2004. Escola de Desempenho de Equitação. Portal Desempenho. Acessado em 10/11/2010. Disponível em: http://www.desempenho.esp.br/noticia/get_noticia.cfm?id=117 6.

57 Ling GN. The physical state of water and ions in living cells and a new theory of the energization of biological work performance by ATP. Molecular and Cellular Biochemistry. 1977;15(3):159-172.

58 Porto LGC, Creppe RC. Modelo Matemático para analisar o desempenho dos motores elétricos em máquinas de processamento de arroz. Departamento de Engenharia Elétrica, Faculdade de Engenharia de Bauru - Universidade Estadual Paulista - UNESP, Bauru. Acessado em 10/11/2010. http://www.feagri.unicamp.br/energia/agre2002/pdf/0010.pdf.

59 Crow K. Product development metrics. DRM Associates. Acessado em 10/11/2010. Disponível em: http://www.npd-solutions.com/pdmetrics.htm.

60 Hill J. System Performance Management - Moving from Chaos to Value. - Team Quest Corporation and Kemer Thomson - Sun Microsystems, Inc. Sun BluePrints OnLine - July 2001. Acessado em 10/11/2010. Disponível em: http://www.oracle.com/us/sun/index.htm.

61 Lourenzani WL. Modelo Dinâmico para a Gestão Integrada de Empreendimentos Rurais. Administração de Empresas e Agronegócios. Universidade Estadual Paulista UNESP/Tupã. Acessado em 11/11/2010. Disponível em:

http://www.upis.br/dinamicadenegocios/arquivos/17\%20artigo\%20

final\%20_Wagner\%20Luiz\%20Lourenzani_.pdf.

62 Jesus L. Medição de Desempenho de Processos. ABPM - Association of Business Process Management Professionals. Disponível no portal Elo Group. Acessado em 10/11/2010. Disponível em: http://www.elogroup.com.br/download/abpmp_ medicao_desempenho_processos_v060808.pdf.

63 Bergamini CW, Beraldo DGR. Avaliação de desempenho humano na empresa. 4.ed.São Paulo: Atlas, 1988.

64 Siqueira W. Avaliação de desempenho: como romper amarras e superar modelos ultrapassados. Rio de Janeiro: Reichmann \& Affonso Editores. 2002, 182 p.

65 Barbosa L. Meritocracia à brasileira: o que é desempenho no Brasil?. Revista do Serviço Público 1996; 120(3):58-102.

66 Neto AS, Gomes RM. Reflexões sobre a avaliação de desempenho: uma breve análise do sistema tradicional e das novas propostas. Revista Eletrônica de Ciência Administrativa (RECADM) 2003; 1(1):1-24.

67 Champagne F. Defining a model of hospital performance assessment for European hospitals. Barcelone: WHO regional office for Europe; 2003. 
68 Klazinga N. Health system performance management: quality for better or for worse. Eurohealth 2010; 16(3):26-28.

69 Hoffman SJ, Røttingen JA, Bennett S, Lavis JN, Edge JS, Frenk J. Background paper on conceptual issues related to health systems research to inform a WHO global strategy on health systems research. 2012.

70 Smith PC, Papanicolas I. Health system performance comparison: an agenda for policy, information and research. World Health Organization (WHO). World Health Organization, on behalf of the European Observatory on Health Systems and Policies 2012.

71 Narvai PC. Pós-graduação, Sistema Qualis e futebol. Revista ADUSP. 2009; 51-56.

72 Santos L. A gestão interfederativa encontrando institucionalidade mediante atos legistativos e regulamentares. In: . Sistema Único de Saúde: os desafios da gestão interfederativa. Campinas SP: Editora Saberes, 2013, p. 167-240.

73 Mendes EV. As redes de atenção à saúde. Brasília: Organização Pan-Americana da Saúde, 2011. 549 p.

74 Brasil. Ministério da Saúde. PROADESS - Avaliação de Desempenho do Sistema de Saúde Brasileiro: indicadores para monitoramento. Relatório final (versão para discussão) Laboratório de Informações em Saúde - LIS Instituto de Comunicação e Informação em Ciência e Tecnologia - ICICT. Fundação Oswaldo Cruz, Rio de Janeiro, 2011. 257p.

75 Duarte HG. Pós-positivismo jurídico: o que pretende afinal? Acessado em: 21/10/2013. Disponível em: http://www.egov.ufsc.br/portal/conteudo/p\%C3\%B3s-positivismojur\%C3\%ADdico-o-que-pretende-afinal.

76 Castanheira Neves, A. Digesta: escritos acerca do direito, do pensamento jurídico, de sua metodologia e outros. Coimbra Editora, 1995. vol. II.

77 Lemos RDD. A dignidade da pessoa humana: conteúdo, limites e possibilidades. Rev. Disc. Jur. Campo Mourão, 2008; 4(2): 41-63.

78 Franco JA. A justiça de Rawls e o pós-positivismo. Acessado em: 01/12/2013. Disponível em: http://intranet.viannajr.edu.br/revista/dir/doc/art_20001.pdf.

79 Galuppo MC. A epistemologia jurídica entre o Positivismo e o Pós-Positivismo. Revista do instituto de hermenêutica jurídica. 2005; 1(3):195-206. 
80 Fontoura JFS, Lima DS, Silva AC, Filho ACM, Souza JC, Eugenio RV. Hermenêutica constitucional e pós-positivismo: notas sobre a metódica estruturante e sobre a técnica da ponderação. Anais do IX Simpósio Nacional de Direito Constitucional. Acessado em: 01/12/2013. Disponível em: http://www.abdconst.com.br/ revista3/joinville.pdf.

Recebido em: 26/7/2016 Aprovado em: 5/12/2016

\section{Como citar este artigo:}

Carnut L, Masseran JAM. O desempenho no Decreto 7.508/2011 e o direito ao acesso aos serviços de saúde: caminhos para uma interpretação pós-positivista. Revista Cadernos Ibero-Americanos de Direito Sanitário. 2016 out./dez, 5(4):123-144. 